\title{
Perceived Locus of Causality and Internalization: Examining Reasons for Acting in Two Domains
}

\author{
Richard M. Ryan and James P. Connell \\ University of Rochester
}

\begin{abstract}
Theories of internalization typically suggest that self-perceptions of the "causes" of (i.e., reasons for) behavior are differentiated along a continuum of autonomy that contains identifiable gradations. $A$ model of perceived locus of causality (PLOC) is developed, using children's self-reported reasons for acting. In Project 1, external, introjected, identified, and intrinsic types of reasons for achievementrelated behaviors are shown to conform to a simplex-like (ordered correlation) structure in four samples. These reason categories are then related to existing measures of PLOC and to motivation. A second project examines 3 reason categories (external, introject, and identification) within the domain of prosocial behavior. Relations with measures of empathy, moral judgment, and positive interpersonal relatedness are presented. Finally, the proposed model and conceptualization of PLOC are discussed with regard to intrapersonal versus interpersonal perception, internalization, causereason distinctions, and the significance of perceived autonomy in human behavior.
\end{abstract}

A central issue for theories of motivation concerns the perceived locus relative to the person of variables that cause or give impetus to behavior. Heider (1958) introduced the concept of perceived locus of causality (PLOC) primarily in reference to interpersonal perception, and more specifically with regard to the phenomenal analysis of how one infers the motives and intentions of others. He distinguished between personal causation, the critical feature of which is intention, and impersonal causation, in which environments, independent of the person's intentions, produce a given effect.

DeCharms (1968) elaborated and extended Heider's phenomenal analysis, particularly with regard to the explanation of behavior (as opposed to outcomes). DeCharms argued that there is a further distinction within personal causation or intentional behavior between an internal PLOC, in which the actor is perceived as an "origin" of his or her behavior, and an external $P L O C$, in which the actor is seen as a "pawn" to heteronomous forces. The distinction between internal and external PLOC has since been crucial for studies of intrinsic versus extrinsic motivation and of perceived autonomy more generally (Deci \&

This work was supported in part by National Institute of Child Health and Human Development Grant HD 19914 to the Human Motivation Program at the University of Rochester.

We would like to thank all the members of the Motivation Research Group who made contributions to this project, especially Rachel Avery, Wendy Grolnick, John Lynch, Christina Frederick, Cynthia MellorCrummey, James Wellborn, Elizabeth Whitehead, and Edward Deci.

Correspondence concerning this article should be addressed to Richard M. Ryan, Department of Psychology, University of Rochester, Rochester, New York 14627.
Ryan, 1985). It has also been applied to both interpersonal attribution processes and issues of self-perception.

As deCharms (1968) pointed out, however, there is an enormous difference between interpersonal attributions of causality and knowledge of the causes of one's own behavior, a difference that "lies at the center of all motivation theory" (p. 319). The most central difference concerns the access an actor has to his or her own internal states versus an observer's reliance on external conditions in the understanding of others' behavior. 'Bridgman (1959) and others have argued that one does not need to observe one's own behavior to verify that it is motivated or autonomous. An individual can know the motivational status of his or her actions directly, precisely because it is he or she who enacts them. However, observations are the primary data for making inferences about the motives and autonomy of others. Lacking direct access to the internal states of others, interpersonal perceivers rely more heavily on the absence or presence of environmental factors and their correlation with action.

Given these considerations, we suggest that the referent of the PLOC metaphor often differs in the case of interpersonal perception versus that of self-knowledge. In interpersonal perception, PLOC is internal or external with respect to the person, who is a socially definable, visible entity (Strawson, 1959). By contrast, in the realm of self-knowledge PLOC pertains to the self, a phenomenal center of personal experience and agency that is not isomorphic with the person or with physical being (Benson, 1987; Deci \& Ryan, 1987; Harre, 1984; Pfander, 1967). It is the degree to which action is initiated and endorsed

\footnotetext{
${ }^{1}$ See Bem (1972) for an alternative viewpoint, namely, that people know their internal states primarily through observation of their behavior and the conditions under which it occurs.
} 
from this phenomenal center that describes the relative autonomy of an act.

The change in referent for the PLOC metaphor between interpersonal and intrapersonal phenomenal analyses has significant ramifications. The most apparent issue is the more differentiated nature of self-knowledge. From the perspective of the self, forces within the person may be experienced as compelling or heteronomous, and thus would not be appropriately described as having an internal locus of causality, even when environmental pressures are clearly absent. Classic cases include behaving from guilt or obligation, that is, when one feels one should or must behave in a given way, rather than feeling that one wants to or chooses to (Lewis, 1971; Ryan, 1982). Here forces, albeit ones internal to the person, are experienced as "acting on" the self, in contrast to the experience of the self as the origin and initiator of action.

Such gradations in the experience of perceived causality with regard to one's own behavior are particularly explicit in theories of internalization (Ryan, Chandler, Connell, \& Deci, 1983). Theories of internalization can be found among diverse schools of thought and fields of study (e.g., Collins, 1977; English \& English, 1958; Kelman, 1958; Lepper, 1983; Meissner, 1981; Parsons, 1952; Rogers, 1965), yet they commonly describe a continuum in which a social value or regulation is adopted as one's own or identified with. The more internalized a value or regulation, the more it is experienced as autonomous or as subjectively located closer to the self (Ryan, Connell, \& Deci, 1985). Internalization theories, however, also typically acknowledge qualitatively distinct motivational states within this continuum of autonomy that bear very definite relations to one another. Thus, for example, in the work of Schafer (1968) and Meissner (1981) the notion of introjection connotes a formerly external regulation or value that has been "taken in" and is now enforced through internal pressures such as guilt, anxiety, or related self-esteem dynamics. Through introjection, reliance on environmental regulation is minimized and replaced by new and quite different affective determinants and qualities. However, it still retains a quality of pressure and conflict, or a lack of complete integration with the self. Introjection is posed as an intermediate form of regulation, between external control and behaving from values or regulations that have been identified with or fully assimilated. Similarly, Kelman (1958) described three different processes by which an individual adopts a value or accepts influence: compliance, identification, and internalization. In his model, compliance involves expectation of rewards or avoidance of punishment, identification is based in conforming to an influence in order to maintain a relationship, and internalization represents the adoption of an influence or value as one's own belief. Here too is a model that suggests varied types or stages of a process of adoption by the self of a practice or value.

Despite the strong influence such formulations have had within psychological theory and clinical practice, there are very few empirical methods for examining either the degree of internalization or the relative autonomy of a given set of values or behavioral regulations. In this article, we propose that the constructs described in internalization theories can be related to several distinct classes of reasons for acting that in turn have a lawful internal ordering. That is, these classes of reasons can be meaningfully placed along a continuum of autonomy, or of selfcausality.

Buss (1978) pointed out that many studies of self-perception confuse the issues of the causes and the reasons related to action. Actors, he argued, typically provide reasons rather than causes when explaining their actions; they state their goals or purposes for doing something. Observers, in contrast, have the option of either reason explanations or causal (person-environment) attributions when construing the actions of others. Thus, we chose to examine reasons in these studies because (a) they are phenomenally accessible, and (b) they represent the primary basis by which people typically account for their own actions. It is, however, important to note the sharp distinction between reasons one is willing or able to endorse regarding one's actions and the "actual" causes or "real" motives behind one's behavior (Peters, 1958). Because our central concern is the perceived locus of causality for one's actions, the status of our variables as real causes or motives is not directly relevant. Instead, our focus is more on how persons understand and describe their own purposes for acting and the relation of such purposes to a continuum of autonomy.

To examine the structure of reasons in relation to one another we first constructed answers to why questions regarding significant behaviors in two domains (achievement and prosocial) that we expected a priori to reflect various levels of internalization. External reasons were those where behavior is explained by reference to external authority, fear of punishment, or rule compliance. Introjected reasons were framed in terms of internal, esteem-based pressures to act, such as avoidance of guilt and shame or concerns about self- and other-approval. Identifications were captured by reasons involving acting from one's own values or goals, and typically took the form of "I want." Finally, and where applicable, we included intrinsic reasons for action where the behavior is done simply for its inherent enjoyment or for fun. Subjects were asked to endorse these reasons to the extent that they explained their own behavior. From this data we examined the interrelations among classes of reasons. $^{2}$

We then propose that an appropriate model for describing perceived locus of causality for one's own actions conforms to a simplexlike or ordered correlation structure. The simplex concept is derived from Guttman's (1954) radex theory, which describes ordered relations between correlated variables. In a simplex, variables are ordered in terms of complexity or conceptual similarity, such that those deemed more similar correlate more highly than those that are hypothetically more discrepant. When arranged in a matrix, a perfect simplex model evidences its largest correlations along a main diagonal, and these increasingly taper off as one moves away from that diagonal. Guttman argued that a simplex model reflects an ordered arrangement along a parameter of variables that also embody qualitative differences. Put differently, simplex models reflect constructs that differ both in kind and degree.

\footnotetext{
${ }^{2}$ Our original model involved seven levels for the academic domain and six levels for the prosocial domain. Although generally reliable, we determined that four and three levels, respectively, displayed better psychometric properties and were more parsimonious for purposes of theoretical exposition.
} 
A true simplex, according to Guttman (1954), should contain at least five variables. This constraint is due to the fact that an ordered arrangement of correlations is more easily observed when there are a sufficient number of entries, and because Guttman relied primarily on an "eyeball" analysis. Because the classes of reasons explored herein are fewer than five, we propose to demonstrate merely a simplexlike arrangement of correlations between reason categories. We test this proposition by using a simple mathematical model. Viewing PLOC through such a model offers certain advantages over the traditional factor analytic approaches. First, it preserves the integrity of various categories of reasons while displaying their interconnection. In addition, it manifests the inherent, underlying parameter along which they are arranged. In this case, we have distinct classes of reasons for action, each with unique characteristics, that are hypothesized to lie along a continuum of autonomy. Finally, it avoids the typical approach of contrasting internal and external ends of a continuum while ignoring middleground motives that have relevance to that continuum.

The research reported in this article reflects exploration of reasons for action in two domains, academic achievement and prosocial behavior. These domains were chosen for several purposes. First, they are both areas of behavior where internalization or socialization models have been widely used. Krathwohl, Bloom, and Masia (1974), for instance, argued for the centrality of internalization models in education, as have Ryan et al. (1985) and Connell and Ryan (1984) more recently. In the prosocial area, internalization or developmental models are also prevalent. Among those relevant in various degrees to the current model are those of Kohlberg (1969), Eisenberg (1982), Kelman (1958), Reykowski (1982), and others.

Second, academic achievement and prosocial behavior are fairly independent realms of inquiry, so that the generality of the reason category approach can be examined. Third, these two domains represent areas where we have sought to explore the issue of autonomy as it interfaces with other basic psychological needs-namely, those for competence and relatednessin accord with our more general theorizing (Deci \& Ryan, 1985; Connell \& Ryan, 1987; Ryan, Connell, \& Grolnick, in press; Ryan \& Lynch, 1989). Because of the different methods, variables, and populations explored in each of these domains, the research in each is presented separately before returning to a general discussion of the issues involved in PLOC and the structure of reasons for action.

\section{PROJECT 1: ACHIEVEMENT DOMAIN}

The perceived locus of causality construct has been widely studied in the context of academic achievement. DeCharms (1976), for example, working from his polar variables of origin and pawn, related the PLOC issue to children's motivation and achievement and to teacher behavior. Deci, Nezlek, and Sheinman (1981), also working from a PLOC conceptualization, related teachers' orientations toward autonomy support versus control to children's perceived cognitive competence, self-esteem, and mastery motivation. Ryan and Grolnick (1986), building on the work of both deCharms and Deci, examined children's perceptions of classroom environments along a PLOC dimension and demonstrated both classroom and indi- vidual difference effects. These and other studies attest to the practical import of PLOC within the academic domain.

Examination of PLOC in the current project was based on students' self-reported reasons for engaging in typical academic behaviors. We began by generating a set of behaviors that were both central for academic performance and could reasonably be expected to have varied motivational sources. To do so we surveyed a small number of elementary school teachers who provided us with behavioral categories, from which we chose four: doing homework, working on classwork, trying to answer questions in class, and a global issue of trying to do well in school. We then began informal one-on-one interviews with children in which we asked them why they do each of these four categories of behavior, and recorded their spontaneous answers, using a strategy developed by Chandler and Connell (1987). As expected, some of the reasons reported emphasized external pressures (e.g., " $m y$ teacher would yell at me if I didn't"), and others reflected more internalized values or goals (e.g." "I feel bad when I don't" or "I want to learn as much as I can"). These interviews helped us to ascertain some of the more phenomenologically salient reasons for acting.

On the basis of these interviews and our a priori conceptualization, we developed four categories of reasons for academic achievement behaviors: external, introjected, identified, and intrinsic. The intrinsic category emerged because of children's reports that classwork or schoolwork could be fun or enjoyable. Intrinsic motivation is not typically addressed by internalization theories, as it is innate rather than internalized. Nonetheless, intrinsic reasons for action are salient in schools and represent a high degree of autonomy (Deci \& Ryan, 1985, 1987). We defined them as reasons based on satisfactions inherent in the activity.

\section{Investigation 1-1: Achievement Model Development}

As an initial test of our model, we surveyed 355 children from Grades 3-6 in a suburban elementary school (Sample 1). Each child received a set of four why questions concerning the behaviors listed earlier, followed by a list of reasons. Each reason was rated on a 4-point scale as being very true, sort of true, not very true, or not at all true for the subject. These responses were scored $4,3,2$, and 1 , respectively. There were a total of 34 reasons spread across the four stem questions. With regard to each of the four why stems, item intercorrelations were then computed and inspected for the hypothesized simplexlike patterns of correlations. An example of such a pattern of correlations among four prototypic reasons for doing homework, one from each category, is shown in Table 1. These prototypic reasons, classified as external (E), introjected (IJ), identified (ID), or intrinsic (IN), clearly fit an ordered pattern. From this initial survey, reasons that fit this general pattern were identified, and eight reasons that had insufficient variability or that did not fit the model were discarded. Table 2 lists types of reasons that represent the categories used in the remaining investigations in Projects 1 and 2.

\section{Investigation 1-2: Test of Achievement Domain Model}

In a second stage of our examination of reasons for achieving, we administered the 26-item reason survey derived from the 
Table 1

Simplexlike Pattern of Correlations Among Four Specific

Reasons for Doing Homework (Sample 1, $n=355$ )

\begin{tabular}{|c|c|c|c|c|}
\hline Reason & 1 & 2 & 3 & 4 \\
\hline 1. Because the teacher will yell & 一 & & & \\
\hline 2. Because I'd be ashamed & $.30 * * *$ & - & & \\
\hline 3. Because I want to learn & $.12^{*}$ & $.34 * * *$ & 一 & \\
\hline 4. Because it's fun & $-.16^{* *}$ & .09 & $.41^{* * *}$ & - \\
\hline
\end{tabular}

$* p<.05$. ** $p<.01$. *** $p<.001$.

pilot investigation (1-1) to three diverse elementary school samples (Samples 2-4). The purposes of this investigation were to (a) examine the generality of the proposed structure across a range of school contexts, and (b) test a simple model describing the ordered correlation properties of the reason categories.

\section{Method}

\section{Subjects}

Elementary school subjects were drawn from three heterogeneous school districts in upstate New York. The urban sample (Sample 2; $n=$ 112) represents primarily lower- to middle-class families, approximately $65 \%$ of whom are minorities. Subjects were from Grades 4-6. The suburban sample (Sample 3; $n=156$ ) consists of 3rd-through 6thgrade children from primarily middle- to upper-middle-class White families. The rural sample (Sample $4 ; n=450$ ) consists of children in Grades 3-6 from a school district approximately 60 miles outside of an urban center. It represents primarily a lower- to middle-class White population. For all samples, there was approximately the same number of students, equally distributed by sex, at each grade level.

Table 2

Examples of Reasons Defining External, Introjected, Identified, and Intrinsic Categories

External (rule following; avoidance of punishment)

Because I'll get in trouble if I don't

Because that's what l'm supposed to do

So that the teacher won't yell at me

Because that's the rule

So others won't get mad at me

Introjection (self- and other-approval; avoidance of disapproval)

Because I want the teacher to think I'm a good student

Because I will feel bad about myself if I don't

Because I'll feel ashamed of myself if I don't

Because I want the other students to think I'm smart

Because it bothers me when I don't

Because I want people to like me

Identification (self-valued goal; personal importance)

Because I want to understand the subject

Because I want to learn new things

To find out if I'm right or wrong

Because I think it's important to . . .

Because I wouldn't want (like) to do that (negative behavior)

Intrinsic (enjoyment; fun)

Because it's fun

Because I enjoy it

\section{Administration Procedures}

All administrations of the reasons survey were conducted by two examiners, one who read aloud standardized instructions and items, and a second who assisted by circulating in the classroom to answer students' questions. The questionnaires were administered in the children's classrooms with the number of students ranging from 18 to 30 depending on the sample. The survey was typically administered concurrently with other instruments (see Investigations 1-3 and 1-4).

\section{Results}

Means for the 26 reasons varied considerably and ranged from 2.01 to 3.62: Standard deviations indicated adequate variability for all items and ranged from approximately 0.67 to 1.17 .

Across the three samples, reasons categorized as identified were most strongly endorsed $(M=3.23)$, followed by external $(M=2.85)$, introjected $(M=2.71)$, and intrinsic $(M=2.32)$ reasons. Thus, the largest difference in mean level between any two categories is between the identified and intrinsic reasons, indicating that children in this age range clearly discriminate between these two types of reasons. Internal consistency estimates $(\alpha)$ for each reason category ranged from .62 to .82 , indicating moderate to high levels of internal consistency within all three samples.

As previously discussed, the pattern of intercorrelations among reason categories was expected to form an ordered pattern in which those categories adjacent along a theoretically specified continuum of autonomy were expected to correlate more highly than those more distant along the continuum. The intercorrelations among the four categories are presented in $\mathrm{Ta}-$ ble 3. In all three samples, the proposed pattern is in evidence.

To evaluate this pattern for congruency with our simplexlike or ordered correlation model, we devised the following statistical tool. First, we assigned an adjacency index to the correlations between reason categories according to how close the

Table 3

Intercorrelations Among Academic Reason Categories for Three Samples of Elementary School Children (Numbers Above Diagonals Represent Disattenuated Correlations)

\begin{tabular}{|c|c|c|c|c|}
\hline Sample & 1 & 2 & 3 & 4 \\
\hline \multicolumn{5}{|c|}{ Urban (Sample 2, $n=112$ ) } \\
\hline 1. External & - & .44 & .15 & .05 \\
\hline 2. Introject & $.34^{*}$ & - & .74 & .22 \\
\hline 3. Identification & .10 & $.53^{*}$ & 一 & .68 \\
\hline 4. Intrinsic & .04 & .17 & $.46^{*}$ & - \\
\hline \multicolumn{5}{|c|}{ Rural (Sample 3, $n=450$ ) } \\
\hline 1. External & - & .70 & .44 & .03 \\
\hline 2. Introject & $.54^{*}$ & - & .78 & .32 \\
\hline 3. Identification & $.30^{*}$ & $.56^{*}$ & 7 & .69 \\
\hline 4. Intrinsic & .02 & $.25^{*}$ & $.47^{*}$ & - \\
\hline \multicolumn{5}{|c|}{ Suburban (Sample 4, $n=156$ ) } \\
\hline 1. External & - & .45 & -.19 & -.41 \\
\hline 2. Introject & $.35^{*}$ & - & .64 & .09 \\
\hline 3. Identification & -.13 & $.46^{*}$ & - & .75 \\
\hline 4. Intrinsic & $-.30^{*}$ & .07 & $.51^{*}$ & - \\
\hline
\end{tabular}

$* p<.001$. 
reason categories are along a continuum of autonomy, as follows: $r_{\mathrm{E}, \mathrm{IJ}}=3, r_{\mathrm{E}, \mathrm{ID}}=2, r_{\mathrm{E}, \mathrm{IN}}=1, r_{\mathrm{IJ}, \mathrm{ID}}=3, r_{\mathrm{IJ}, \mathrm{IN}}=2$, and $r_{\mathrm{ID}, \mathrm{IN}}=3$. Then we computed the amount of variance accounted for by this adjacency index in the obtained squared correlations among the reason categories. Squared correlations were used in order to restore interval scale properties to this data so as to meet the assumptions of a correlational test. This analysis resulted in a congruency coefficient of $.79(p<.01)$, demonstrating that more than $60 \%$ of the variance in squared correlations is accounted for by the adjacency index.

To assess whether the match of the obtained pattern of correlations to the simplexlike model is a function of the subscales' internal consistencies (reliabilities), we calculated the reliability-corrected or disattenuated correlations (McNemar, 1962) between subscales, shown in Table 3 . They indicate that the simplexlike pattern is not a function of differential reliabilities.

To further consider the utility of the simplex-type model and conceptualization of PLOC, we also examined the alternative factor analytic approach. Typically, PLOC has been considered either as a single dimension or as a contrast between external or extrinsic motives and intrinsic or internal motives (thereby omitting consideration of "middle-ground" motivational states). Such an approach is not only appropriate, it can also result in a "clean" factor analytic model.

In exploratory analyses, we subjected the 26-item academic survey in our largest sample (Sample $4, n=450$ ) to varied factor analyses. A meaningful two-factor solution emerged with a first factor anchored at the internal end and a second at the external end of the PLOC continuum. Middle-ground items, that is, introjection and some from the identified category, generally manifest a cross-loading pattern. Using a liberal cutoff of .45 for scale inclusion and .3 for maximal cross-loading resulted in two clean subscales, one internal and one external. The External subscale consisted of five external category items and one introjected item. The Internal factor consisted of four intrinsic, three identified, and one introjected item. Undoubtedly these two subscales, representing opposite ends of the PLOC continuum, would demonstrate good discriminant validity and relate meaningfully to external criteria. However, meaningful psychological categories would fail to be considered because of the procrustean bed of this factor analytic approach.

By organizing motives into graded categories, we suggest in turn that so-called discriminant validity will in some cases be less robust than by the polar factor approach. In fact, lower discriminant validity between adjacent categories and greater discriminant validity for more distant subscales is the type of pattern that would support our conceptualization of the PLOC model. Patterns of external validity are therefore explored in the subsequent investigation.

\section{Investigation 1-3: Correlations With Dimensions of Related Interest}

The underlying concept of the PLOC model is that of autonomy. An external PLOC describes the circumstance of experienced control or compulsion by others, whereas an internal PLOC is accompanied by felt volition and autonomy. Most existing treatments of constructs relevant to PLOC reflect these two extremes, and are indeed operationalized as polar variables.
Harter (1981) introduced a polar scale of intrinsic versus extrinsic motivation in the classroom that we have used in much of our previous work (Deci et al., 1981; Harter \& Connell, 1984; Ryan \& Grolnick, 1986). The scale is a self-report measure that pits an intrinsic orientation against an extrinsic orientation. Three of the components (curiosity, independent mastery, and preference for challenge) make up a factor that Harter (1981) and Harter and Connell (1984) have referred to as mastery motivation (18 items). Mastery motivation is by definition accompanied by an internal PLOC (Deci \& Ryan, 1985); therefore, we expected high correlations between Harter's measure and both our Identified and Intrinsic subscales. In addition, we expected a negative correlation with our external PLOC category. However, we predicted no correlation with our introjected items, as introjected motives are not reflected by either pole of the Harter construct.

DeCharms (1976) introduced a polar construct of perceived classroom contexts that varies from the perception that one is a pawn in the classroom to the perception that one is an origin (or has autonomy). Although this device is typically used to describe differences between classrooms by using subjects' average scores, Ryan and Grolnick (1986) have shown that the variance from origin to pawn is also reflective of individual differences within classrooms. We expected that the deCharms measure would be negatively correlated with external reasons, uncorrelated with introjection, and positively and significantly correlated with the Identified and Intrinsic subscales.

Perceived control over outcomes, although conceptually distinct from perceived locus of causality (deCharms, 1981; Deci \& Ryan, 1987; Ryan \& Grolnick, 1986), is also often described in terms of internal versus external loci. Perceived control over outcomes pertains to one's beliefs about who or what controls outcomes. More specifically, internal perceived control connotes a belief that one's behavior is reliably linked to outcome attainment, and external perceived control describes the belief that outcomes and behavior are independent. In principle, one can believe that one's behavior would reliably lead to a given outcome (e.g., good grades in school) but still experience little autonomy in initiating the behavior (e.g., study only out of external pressure to do so).

Despite the important distinctions between perceived locus of control and PLOC, the two dimensions are hypothesized to be systematically related to each other. We suggest that the process of internalizing a value or behavioral regulation is more likely to occur if one has adopted the belief that relevant outcomes are potentially under one's control. Thus, we expect that the reason categories representing internalization, that is, introjection and identification, will be positively related to a perceived internal locus of control. Furthermore, one is more likely to be intrinsically oriented to a task for which one believes that outcomes are controllable. In contrast, an external locus of causality should be uncorrelated with internal perceived locus of control, as one's perceived lack of autonomy may or may not be associated with beliefs about behavior-outcome dependence.

Recent work on children's control beliefs suggests that internal and external locus of control perceptions have distinct developmental paths and are most appropriately considered as independent of each other (Connell, 1985; Skinner \& Chapman, 
1987). Accordingly, in the present study, we focus only on the degree to which subjects perceived control over outcomes to be internal. Furthermore, we restricted inquiry to academic (cognitive) outcomes, as our PLOC measure is itself focused on the cognitive domain. To operationalize control, then, we used Connell's (1985) multidimensional measure of children's perceptions of control, which both treats the dimension of perceived internal control separately and has a subscale specific to the academic domain.

Finally, to gain an independent rating of subjects' motivation and performance in relation to their endorsement of the four reason categories, mothers, fathers, and teachers in the rural sample (Sample 4) were asked to gauge the subjects' motivation and competence through a brief questionnaire. We expected that there would be a positive relation between all three "nonexternal" categories (i.e., introjected, identified, and intrinsic) and ratings of motivation, as all represent varied internal motives for action, and no relation was expected for external reasons and rated motivation. Indeed, external agents who must provide external pressures or incentives for a student to induce achievement behaviors are unlikely to view the recipients of these controls as motivated. To establish the discriminant validity of the PLOC measure, ratings of child competence are also presented, although we anticipated no relation of reasons and rated competence.

\section{Method}

\section{Subjects}

Subjects were the urban ( $n=113$ ), suburban ( $n=152)$, and rural $(n=450)$ samples described in Investigation 1-2 (i.e., Samples 2-4, respectively).

\section{Procedure}

All sessions were administered by two trained examiners, using procedures previously specified. Procedures regarding teacher, mother, and father ratings of motivation and competence are described later.

\section{Measures}

Intrinsic Versus Extrinsic Orientation in the Classroom Scale (Harter, 1981). This is a 30-item, self-report instrument designed to assess five components of children's intrinsic versus extrinsic orientation toward school work, using a structured alternative format that first pits an intrinsic orientation against an extrinsic orientation and then asks the child to make a second 2-point judgment as to whether the selected statement is "really true" or "sort of true." Three of the components (curiosity, independent mastery, and preference for challenge) have been combined into a single mastery motivation score for use in this study. The alpha reliability of this 18 -item composite was .88 .

Multidimensional Measure of Children's Perceptions of Control (Connell, 1985). This is a 48-item, self-report questionnaire. It yields separate subscale scores on 4-point scales for internal, powerful others, and unknown perceptions of control over positive and negative outcomes within three behavioral domains (cognitive, social, and physical) and in general. Our focus in this study was on the dimension of internal perceived control over outcomes in the cognitive (school) domain. The alpha reliability of this variable is reported by Connell (1985) as .56. Additionally, Connell reported extensive evidence of the scale's reliability and validity.
Origin Climate Questionnaire (deCharms, 1976). This questionnaire assesses children's perceptions of the origin (autonomy-supportive) versus pawn (controlling) orientation of their teacher and classroom environment. This measure contains 28 items, with 4 items associated with each of seven subscales: Internal Control, Goal Setting, Instrumental Activity, Reality Perception, Personal Responsibility, Self-Confidence, and Warmth. The items are presented in a Likert-type format, and are phrased in terms of teachers' behavior or things that happen in the classroom. The child circles the choices always, often, sometimes, or never. The items constituting each subscale are summed to form seven subscale scores. Subscale scores, except Warmth, are then summed to yield a total Origin Climate score.

Mother-, father-, and teacher-rated motivation of the children. We obtained these ratings through a brief (16-item) questionnaire. Parents received the questionnaire in their children's report-card envelopes, with a separate form included for mother and father. Approximately $60 \%$ of the subjects had at least one parent who returned the survey (243 mothers and 190 fathers). An identical survey was also completed by classroom teachers for 403 children. Eight of the items on the survey concerned child motivation and competence, and eight items concerned parenting-teaching practices with regard to the child. Of the eight child items, only those concerning motivation (three items) and competence (two items) were used in the current analyses. Parents and teachers rated these characteristics on 4-point Likert-type scales.

\section{Results}

Correlations of the Harter (1981), Connell (1985), deCharms (1976), and motivation rating variables with the simplexlike model are presented in Table 4 . In general, these results support the hypothesized pattern of relations. As expected, both the Harter (1981) and deCharms (1976) measures manifested a graded series of correlations with the PLOC subscales. In contrast, perceived internal control was most strongly correlated with the two middle, internalized subscales of introjection and identification in both urban and suburban samples, with less robust relations between control beliefs and either intrinsic or external categories. Also, the more adjacent the subscale, the more similar the correlation with external criteria, as expected from this model.

Correlations of father $(n=188)$, mother $(n=243)$, and teacher $(n=403)$ ratings of motivation within the rural sample and the reason categories are reported in Table 5 . In addition, for purposes of discriminative validity, ratings of competence are also presented. As shown by the pattern of results, child endorsement of internalized reasons for achievement-related behaviors is associated with being rated as more motivated by adults, and external reasons for action are uncorrelated or negatively related. In contrast, competence ratings are generally not associated with internalized reason categories, and the external reason category related negatively to father- and teacher-rated competence.

\section{Investigation 1-4: Relations With Coping, Anxiety, Effort, and Enjoyment}

As a final step in explicating the relations between reason categories in the achievement domain and variables related to autonomy and self-regulation, we investigated the correlations between the reason variables and self-reported styles of coping with failure, anxiety, effort, and enjoyment in school. We sug- 
Table 4

Correlations Between Academic Reason Categories and Mastery Motivation (Harter, 1981), Perceived Internal Control for Cognitive (School) Outcomes (Connell, 1985), and Perceived Classroom Climate (deCharms, 1976)

\begin{tabular}{lcccc}
\hline \multicolumn{1}{c}{ Sample } & External & Introjected & Identified & Intrinsic \\
\hline Urban (Sample 2, $n=113$ ) & & & & \\
$\quad$ Classroom climate & $-.19^{* *}$ & -.02 & $.20^{* *}$ & $.41^{* * *}$ \\
$\quad$ Internal control-cognitive & .06 & $.25^{* * *}$ & $.17^{*}$ & .02 \\
Suburban (Sample 3, $n=152$ ) & $-.41^{* * *}$ & .04 & $.50^{* * *}$ & $.54^{* * *}$ \\
$\quad$ Mastery motivation & .11 & $.30^{* * *}$ & $.44^{* * *}$ & $.18^{* *}$ \\
$\quad$ Internal control-cognitive & -.04 & $.18^{* * *}$ & $.29^{* * *}$ & $.22^{* * *}$ \\
Rural (Sample 4, $n=450$ ) & & & \\
Classroom climate & & &
\end{tabular}

gest that the different types of motivational processes involved in endorsing the various reason categories should be manifest in the ways in which a student defends against or copes with failure experience. Thus, we predicted that the externally motivated student would use "externalizing" coping strategies such as projection (blaming the teacher) or denial (it's not important) in the face of failure. In contrast, introjected and identified types of motives for achievement would be associated with positive coping strategies, that is, acting to ensure future success and prevent failure. Finally, introjection was expected to be associated with amplified anxiety and self-disparagement following failure (e.g., worrying about future failures, feeling "stupid," etc.). In addition, because introjected motivation is based in internal, self-esteem-based affects, this category was expected to be correlated with anxiety over cognitive outcomes more generally. To examine these hypotheses, we used Tero and Connell's (1984) coping inventory for the academic domain that taps four types of response-to-failure outcomes (positive coping, denial, projection [blame], and anxiety amplification) and Buhrmester's (1980) survey assessing children's domain-specific anxiety.

As a further assessment of the motivational aspects of the PLOC model, students were asked to rate their enjoyment and effort with regard to behaviors of interest. We expected that enjoyment would show a linear pattern of relations with the four

Table 5

Correlations Between Academic Reason Categories and Mother-, Father-, and Teacher-Ratings of Subjects' Motivation and Competence (Sample 4)

\begin{tabular}{|c|c|c|c|c|}
\hline Rating & External & Introjected & Identified & Intrinsic \\
\hline \multicolumn{5}{|c|}{ Mother $(n=243)$} \\
\hline Motivation & .09 & $.16^{* *}$ & $.17^{* * *}$ & $.22^{* * * *}$ \\
\hline Competence & -.04 & .01 & .07 & .07 \\
\hline \multicolumn{5}{|l|}{ Father $(n=190)$} \\
\hline Motivation & .06 & $.19^{* *}$ & $.26^{* * *}$ & $.22^{* * *}$ \\
\hline Competence & $-.14^{*}$ & .04 & .11 & .11 \\
\hline \multicolumn{5}{|c|}{ Teacher $(n=403)$} \\
\hline Motivation & $-.12^{*}$ & .07 & $.14^{* * * *}$ & $.17^{* * * *}$ \\
\hline Competence & $-.20^{* * *}$ & .02 & .05 & $.10^{*}$ \\
\hline
\end{tabular}

${ }^{*} p<.05 .{ }^{* *} p<.01 . \quad{ }^{* * *} p<.001$. reason categories, whereas effort would be correlated with all three nonexternal subscales, that is, introjected, identified, and intrinsic.

\section{Method}

\section{Subjects}

Samples 3 and 4 were used. In addition, an urban sample $(n=149$; boys $=73$, girls $=76$ ) of 3 rd-6th graders was used, drawn from the same magnet school represented by Sample 2. This sample (labeled $2 a$ ) was collected in the year following the Sample 2 data collection; thus, subjects in Grades 5-6 largely overlap. However, because of confidentiality procedures there was no way to link the two data collections, and the data are thus treated as independent samples. Questionnaire administration was accomplished by using previously described procedures.

\section{Measures}

Children's Academic Coping Inventory (Tero \& Connell, 1984). This 19-item, self-report scale taps children's cognitive, affective, and behavioral responses to perceived academic failure. Four styles of coping are tapped by the scale: positive coping (the child actively seeks to remedy the causes of the perceived poor performance), projection (blaming the teacher or others for perceived failure), denial of the significance of the failure, and anxiety amplification (worrying, self-denigration). Factor analysis of the scale indicates four reliable factors corresponding to the four coping strategies. Alpha reliabilities of the subscales range from .70 to .85 .

Children's Concern Questionnaire (Buhrmester, 1980). This questionnaire contains 28 items designed to tap the degree to which children are anxious about outcomes associated with school activities. Four 7item subscales tap children's worrying about test performance, peer acceptance, physical activities, and school conduct on 4-point Likert scales. Only the Test Performance Concerns subscale was used in this study. The alpha reliability of the subscale is .79 .

Enjoyment rating. Children were asked to rate the statements "I enjoy doing my classwork," "I like doing my homework," and "I enjoy answering hard questions in class," each on a 4-point scale (very true, sort of true, not very true, not at all true). The alpha reliability of the three-item composite is $\mathbf{7 4}$.

Effort rating. Children were also asked to rate the statement "I try hard to do well in school" on the same 4-point scale as just described.

\section{Results}

Sample 2a was inspected for its fit with the simplexlike correlation pattern. As expected, the intercorrelations between rea- 
son categories fit the model. Table 6 presents the correlations between the various reason categories and the measures of coping, anxiety, effort, and enjoyment of school within the three samples. Positive coping was positively related to all three nonexternal reason categories, and denial and projection were related in two of the three samples to the external reason category. Projection was also negatively correlated with identification in these two samples. Furthermore, as predicted, anxiety amplification was most strongly related to the introjected category in all samples. Buhrmester's (1980) anxiety index showed a similar pattern in two of the three samples. Enjoyment and effort ratings fit the expected pattern: Effort was uncorrelated with external reasons for achieving, and all three nonexternal forms of reasons were positively correlated with self-reports of effort. Enjoyment was most strongly associated with intrinsic reasons, a nearly tautological finding. More generally, the more autonomous the reason category, the more it was associated with selfreported enjoyment.

\section{Discussion (Project 1)}

In Project 1, categories of reasons for achievement-related behaviors were identified and tested for their correlational structure in three diverse samples of children in Grades 3-6. The demonstration of a stable structure of reasons across samples attests to the fact that PLOC can be complexly modeled and can incorporate middle-ground levels of autonomy such as introjection. Data showing hypothesized links between the various reason categories and other measures of internal-external causality (i.e., of perceived autonomy) were presented and provided support for the substantive utility of the PLOC continuum herein proposed. Finally, it was shown that the four reason categories systematically and meaningfully related to self-reported coping styles, anxiety, effort, and enjoyment in school and to mother, father, and teacher ratings of child motivation.

The data presented in Project 1 pertain exclusively to the academic domain. In our view, the PLOC continuum should be identifiable in those domains where internalization is at issue. Project 2 was an attempt to investigate this proposition by applying a similar model to a different domain: prosocial behavior.

\section{PROJECT 2: PROSOCIAL DOMAIN}

The motivational and phenomenal basis of prosocial behavior is a topic that has been attracting increased attention from researchers over the past decade (Eisenberg, 1982; Radke-Yarrow, Zahn-Waxler, \& Chapman, 1983; Reykowski, 1982). Although there is much controversy in the field regarding explanatory models of prosocial behavior, several points of general agreement have emerged. The first is that prosocial and moral behaviors should be distinguished from social conventions, particularly in terms of their developmental acquisition (Turiel, 1977). Second, it is clear that prosocial behavior can be motivated by varied processes ranging from egoistic to altruistic and from exogenous to endogenous. Eisenberg-Berg (1979) has, for example, shown that, with age, reasons for prosocial action tend to change from being more hedonistic and approval-oriented toward being more internalized or empathically oriented. Reykowski and Smolenska (1980), in a more categorical approach,

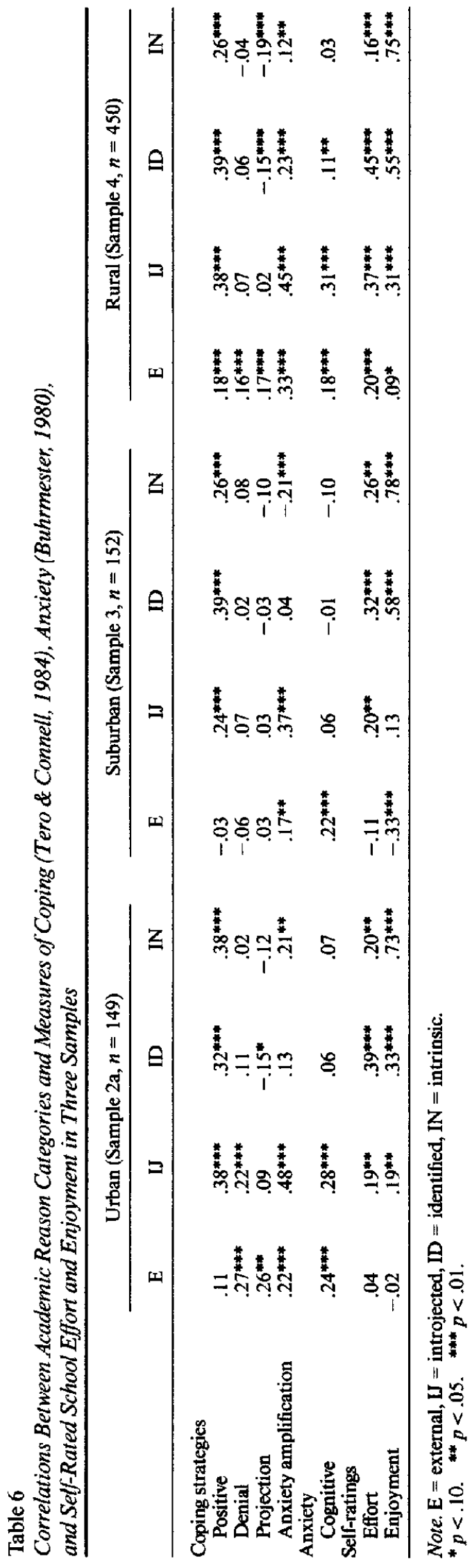


distinguished between ipsocentric, endocentric, and intrinsic prosocial motives. Ipsocentric motives are those involving personal gain (or avoidance of loss), endocentric motives refer to anticipation of self-esteem-relevant outcomes from action, and intrinsic prosocial motives connote a primary focus on the needs of the other, that is, of the external social object.

Such perspectives lend credence to the current proposal that the PLOC for prosocial acts is a relevant dimension within which varied reason categories may be identified. We suggest that, just as in the achievement domain, a person can have reasons for acting prosocially that can be variously construed as external or introjected, or as outcomes of identifications. Indeed, reasons from all three classes of motives have been studied and discussed in the work of Eisenberg-Berg (1979) and others. Our intention in Project 2 was to explore (a) whether these three broad classes of reasons fit an ordered correlation model such as that described in Project 1 , and (b) whether these reason categories show meaningful associations with other dimensions of interest in the prosocial domain.

\section{Investigation 2-1: Prosocial Model Development}

The strategy used in Investigation 2-1 parallels that described in Investigation 1-1, with minor modifications. In the initial survey we selected four prosocial behaviors, two positive and two negative. Subjects were asked why they (a) would keep a promise to a friend, (b) would try to be nice to others, (c) would not hit someone when angry, and (d) would not make fun of another child who makes a mistake. These four were chosen because they were balanced for positive and negative acts, broadly fit within the domain of prosocial behavior, and were understandable to the 9- to 12-year-old subjects who represented our youngest samples.

Insofar as appropriate, the same or similar reasons for behaviors that were used in the achievement domain were applied with regard to these prosocial acts. Thus, we included such reasons as "because I'd get in trouble if I did/did not" (external), "because I'd feel bad about myself if I did/did not" (introjected), and "because I think it is important to. . . ." (identified). However, no reasons reflecting an intrinsic orientation were included in the prosocial survey. It made no sense in the context of this style of survey to say, for example, that one refrains from hitting "because it is enjoyable not to," or that one keeps a promise "because it's fun."

The resulting initial survey included 25 reasons distributed across the four behaviors. We used a response format identical to the achievement survey. These 25 items were administered to 114 fourth- through sixth-graders in an urban Rochester school (the same urban sample described in Investigation 1-2 as Sample 2). Because this was a pilot version of the prosocial survey, it was administered after all other measures were completed.

Results of this pilot survey were examined for empirical fit with the hypothesized simplex model. Of the 25 items, we retained 20 that best exemplified the expected pattern.

Subscale alphas for the three reason categories were $.61, .79$, and .85 for the external (E), introject (IJ), and identified (ID) items, respectively. Intercorrelations between E, IJ, and ID categories reflected a pattern similar to that observed between those categories in Project 1. However, $\mathrm{E}$ and $\mathrm{IJ}(r=.27, p<.01)$ were less closely related than $\mathrm{IJ}$ and $\mathrm{ID}(r=.63, p<.001)$; ID and $\mathrm{E}$ categories were uncorrelated $(r=.05, n s)$. This pattern, therefore, suggests that for this sample introjected and identified reasons are more strongly associated in these subjects' meaning network than are external and introjected items. Nonetheless, introjection retains its character as an intermediate category of reasons that is significantly related to both adjacent categories.

On the basis of these results, we applied our model to subsequent samples for purposes of both generalization and elaboration. Results of these investigations are presented later.

\section{Investigation 2-2: Test of Prosocial Domain Model}

To test the generality of the correlation structure among the three reason categories identified in Investigation 2-1, five samples varying in age and demographics were tested by using prosocial reason surveys. The elementary school sample received the 20 -item version previously described, and high school and junior high school samples received a 25 -item version that included five stems. These stems included the "keep a promise" and "not hit" stems used in elementary schools. In addition, they included three new stems: (a) "Why would you not tell lies to people?" (b) "Why would you help someone in distress?" and (c) "Why would you not steal things from others?" These stems reflected, therefore, both prosocial and moral issues so as to broaden the domain of investigation.

\section{Method}

\section{Subjects}

Sample 5. Sample 5 consisted of urban elementary children drawn from two inner-city, neighborhood-based schools $(N=268)$. The sample ranges from 4 th to 6 th grades, and represents primarily minority children of lower to lower-middle-class socioeconomic status (SES).

Sample 6. This sample was composed of rural junior high school students $(N=186)$ in Grades 7 and 8 from a school district located approximately 40 miles outside of an urban area. This sample comes from a different rural district than that used in Project 1, but also primarily represents children of lower- to lower-middle-class SES.

Sample 7. Rural high school students, Grades 9-12, from the same district as Sample $6(N=304)$, constituted Sample 7 .

Sample 8. This sample consisted of suburban high school students, Grades 9-12, from a first-ring suburb $(N=214)$. Students came from primarily middle- to upper-middle-class backgrounds.

\section{Administration Procedures}

All surveys were administered according to procedures described in Investigation 1-2, with the exception of the suburban high school where only one examiner was involved. In all cases, these surveys were obtained concurrently with other group measures. Those measures relevant to this study of PLOC are discussed in Investigation 2-3.

\section{Results}

Means for the sampled reasons varied considerably, ranging from 2.33 (suburban high school, external category) to 3.48 (urban elementary, identified category). Standard deviations indicated that variability was adequate and ranged from .44 to .82 . As with the results of Project 1 , identified reasons were most 
Table 7

Intercorrelations of Prosocial Reason Categories

in Four Samples (Numbers Above Diagonals

Represent Disattenuated Correlations)

\begin{tabular}{|c|c|c|c|}
\hline Sample & 1 & 2 & 3 \\
\hline \multicolumn{4}{|c|}{$\begin{array}{l}\text { Urban elementary } \\
\quad \text { (Sample } 5, n=268 \text { ) }\end{array}$} \\
\hline 1. External & - & .54 & .22 \\
\hline 2. Introjected & $.37^{* * * *}$ & - & .67 \\
\hline 3. Identified & $.16 * *$ & $.52^{* * *}$ & - \\
\hline \multicolumn{4}{|c|}{$\begin{array}{l}\text { Rural jr. high } \\
\quad \text { (Sample } 6, n=186 \text { ) }\end{array}$} \\
\hline 1. External & - & .48 & .11 \\
\hline 2. Introjected & $.33^{* * * *}$ & - & .87 \\
\hline 3. Identified & .08 & $.68^{* * *}$ & - \\
\hline \multicolumn{4}{|c|}{$\begin{array}{l}\text { Rural high school } \\
\quad \text { (Sample } 7, n=304 \text { ) }\end{array}$} \\
\hline 1. External & - & .68 & .34 \\
\hline 2. Introjected & $.46^{* * * *}$ & - & .88 \\
\hline 3. Identified & $.24^{* * * *}$ & $.69^{* * * *}$ & - \\
\hline \multicolumn{4}{|c|}{$\begin{array}{l}\text { Suburban high school } \\
\quad(\text { Sample } 8, n=214)\end{array}$} \\
\hline 1. External & - & .93 & .20 \\
\hline 2. Introjected & $.64^{* * * *}$ & - & .61 \\
\hline 3. Identified & $.14^{*}$ & $.48^{* * * *}$ & - \\
\hline
\end{tabular}

$* p<.05 . * * p<.01 . * * * p<.001$.

highly endorsed in all samples with sample means for this category ranging from $3.31(S D=0.52)$ to $3.48(S D=0.56)$. Means for the introjected category ranged from $2.75(S D=0.66)$ to $3.09(S D=0.50)$, and those for the external category ranged from $2.33(S D=0.63)$ to $2.82(S D=0.66)$. Internal consistency estimates $(\alpha)$ for Samples 5-8, respectively, were .65, .62, .62, and .62 for the external category; $.77, .79, .82$, and .69 for the introjected category; and $.85, .85, .86$, and .67 for the identified category.

Intercorrelations between the categories of reasons for prosocial acts are presented in Table 7 . In each case, the proposed pattern of correlation appears to be in evidence. However, to further examine this issue, we used the congruency test described in Project 1-2. For the proposed reasons we assigned the following adjacency index: $r_{\mathrm{E}, \mathrm{IJ}}=2, r_{\mathrm{E}, \mathrm{ID}}=1$, and $r_{\mathrm{IJ}, \mathrm{ID}}=2$. We then correlated this adjacency index with the squared correlations. The resulting congruency coefficient was .74 $(p<.001)$, accounting for approximately $55 \%$ of the variance in squared correlations. Table 7 also presents the subscale intercorrelations after disattenuation.

\section{Investigation 2-3: Relations of Prosocial Reasons With Other Dimensions}

Having established evidence in favor of an ordered structure for reason categories underlying prosocial acts, our next endeavor was the investigation of how these reason categories relate to important dimensions relevant to the prosocial domain. In proposing that prosocial acts can be regulated or initiated by quite different motives that vary in terms of PLOC, we also might expect that the conditions that support those reasons differ. Reasons that we classify as identified are marked by one's endorsement of the value of prosocial acts, rather than a focus on norms or personal gain. In contrast, external regulation of prosocial behavior involves a focus on avoidance of punishment or compliance with proscriptions. Self-concern rather than other-concern is therefore more evident in such reasons. We thus hypothesized that the more autonomous the reasons for prosocial action, the more empathy will be associated with them. In Investigation 2-3 we investigated this hypothesis, using a measure of empathy developed by Bryant (1982) for use with adolescents and children.

A second dimension of obvious relevance to the prosocial domain is that of moral reasoning. One of the hallmarks of increasing autonomy (or a more internal PLOC) in one's actions is that more autonomous acts are more fully self-endorsed or valued by the actor (Benson, 1987; Deci \& Ryan, 1987). Thus, to some extent we expected that a more internal PLOC for prosocial acts would be associated with the development of more mature forms of moral reasoning that would support such values. Furthermore, in their most general form, theories of moral reasoning suggest that judgments proceed from simple heteronomous (authority-based) modes to more autonomous modes of prescriptive principles (Kohlberg, 1969). We hypothesized that there should be a modest parallel between the endorsement of more autonomous reasons for engaging in prosocial acts and the development of more autonomous forms of moral judgment. In this study, we assessed moral judgment abilities using the Defining Issues Test (Rest, 1979), a self-report objective measure of moral judgment based on Kohlberg's formulations.

A third variable of interest for its association with the PLOC dimension in the prosocial realm is that of how the quality of relationships with significant adults may be associated with more internalized prosocial values. It has indeed been hypothesized that one of the factors that leads to identification with socially relevant prescriptions is an affective tie with significant others (e.g., Connell \& Wellborn, in press; Parsons, 1952; Ryan et al., in press). Accordingly, we expected that self-reports of positive relatedness with others, particularly parents, would be significantly correlated with identified reason endorsements in the prosocial domain. Associated with this formulation is the idea that one's concern with and ties to others form the basis of concern for others' welfare and well-being, which supplies a motivational basis for prosocial acts.

To test this concept, we examined the relations between our prosocial simplex variables and a measure of positive relatedness to mother, father, and teachers recently developed by Wellborn and Connell (1987). The relatedness construct is based on ratings of seven emotions that one experiences when with the target person. Subjects in both the rural junior high and high school samples (Samples 6 and 7) completed this measure for each of the targets of mother, father, and teacher.

\section{Method}

\section{Subjects and Procedure}

Subjects from Sample 5, urban elementary children $(n=268)$ in Grades 4-6, were given the Bryant (1982) Index of Empathy measure in classroom settings, using procedures previously described. Subjects from Sample 8, suburban high school students $(n=214)$ in Grades 912 , received the Defining Issues Test (Rest, 1979), also within classroom 
settings. Samples 6 and 7 completed the positive relatedness measure (Wellborn \& Connell, 1987) with reference to mother, father, and teachers in classroom settings.

\section{Measures}

Index of Empathy (Bryant, 1982). The index is an adaptation for children and adolescents of items drawn from Mehrabian and Epstein's (1972) measure of empathy for adults. Bryant's adaptation consists of 22 items presenting empathic or nonempathic tendencies to which the child responds with a yes or no answer. The measure includes subscales for empathy with boys, girls, or neutral figures, based on Feshbach and Roe's (1968) idea that children may be more empathic with same-sex figures. Because such gender patterns are not a focus in this investigation, we used the total empathy score. Bryant (1982) reported evidence of the scale's convergent and discriminant validity vis-à-vis other measures of empathy, acceptance of differences in peers, and teacher-rated aggressiveness. This measure was given only in Sample 5.

Defining Issues Test (DIT; Rest, 1979). The DIT is a self-report measure of moral reasoning judgments based conceptually on Kohlberg's theory of the development of moral judgments. The test presents the subject with six vignettes posing varied moral dilemmas, followed by a series of multiple-choice-type items. Scoring is objective and thus highly reliable. The test took approximately $30-40 \mathrm{~min}$. The central score used in this study was Rest's "P" index, which reflects the relative importance the subject gives to "principled" moral considerations in moral decisions, that is, considerations reflecting Kohlberg's Stages 5 and 6. The DIT has been used in well over 500 studies to date, and has extensive and well-established construct validity.

Self-Reported Relatedness to Others (Wellborn \& Connell, 1987). This questionnaire measure consists of a stem stating "When I'm with , I feel" for each social partner (mother, father, teacher[s]), followed by seven emotion labels (e.g., relaxed, ignored, happy), each of which the subject rates on a 4-point scale ranging from almost always to almost never. Factor analyses of the seven-item measure for each partner revealed a single factor of high to low positive relatedness with internal consistencies ranging from .79 to .84 for the various social targets.

\section{Results}

Empathy (Sample 5). We calculated correlations between the prosocial reasons categories and the total empathy score, and they are presented in Table 8 . These results reflect that both "internalized" prosocial categories were associated with empathy.

Moral reasoning (Sample 8). We obtained correlations between prosocial reason categories and measures derived from the DIT; these also appear in Table 8. The P\% score is the central index reflecting use of principled considerations in making moral judgments. Results show that $\mathrm{P} \%$ is significantly correlated only with the identification category of reasons. A secondary index of interest from the DIT is the " $\mathrm{A}$ " index, which reflects antiestablishment attitudes. Exploratory correlations revealed that this was marginally negatively correlated with the introjected category and significantly and negatively associated with the identified reason category.

Relatedness (Samples 6 and 7). Correlations between the three simplex categories for the prosocial domain and the measure of relatedness with regard to mother, father, and teachers are also presented in Table 8. In general, results showed that relatedness to others was positively associated only with en-
Table 8

Correlations of Prosocial Reason Categories With Empathy

(Bryant, 1982), Moral Reasoning (Rest, 1979), and

Relatedness (Wellborn \& Connell. 1987)

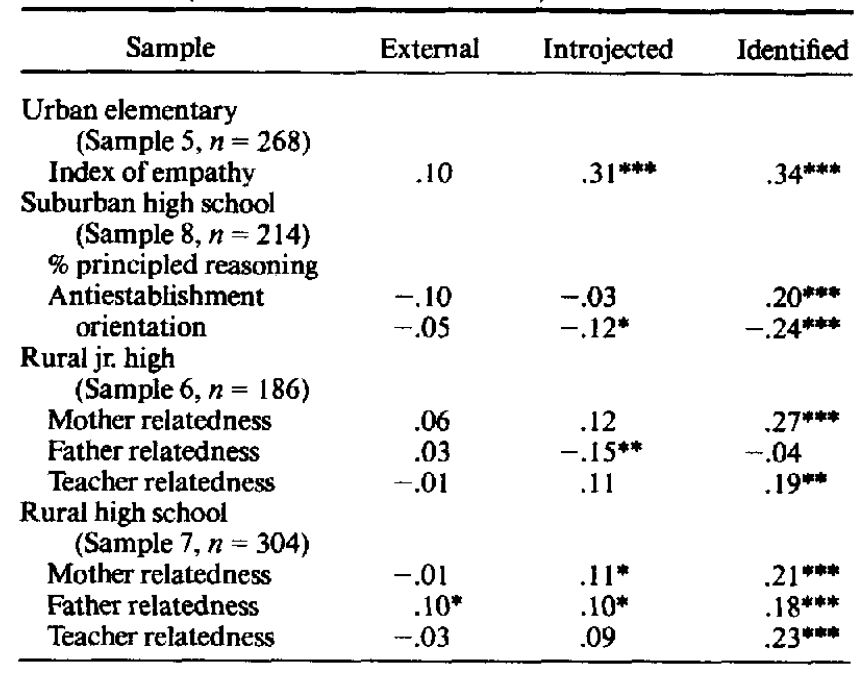

${ }^{*} p<.10 . \quad{ }^{* *} p<.05 . \quad{ }^{* * *} p<.01$.

dorsement of the identified category of reasons for prosocial behaviors.

\section{GENERAL DISCUSSION}

The locus relative to the self of variables that are perceived to determine behavior has been an important dimension in social and personality psychology for more than 3 decades. To the extent that variables external to the self are perceived as giving rise to the initiation or maintenance of an act, then to that degree the act is not experienced as autonomous, and may subsequently depend on the presence of that external PLOC variable for its occurrence. This formulation bears important implications for studies of attitude and behavior change, and for applied motivational studies more generally.

Traditionally the PLOC issue has been studied by contrasting internal and external loci, with the dividing line of this spatial metaphor being the person. Phenomenological reflection, however, attests to the viewpoint that intrapersonal pressures, anxieties, or standards can have, at times, coercive influences on behavior that are not well described by the term autonomy. Furthermore, PLOC has often not focused on the actor's reasons for behavior as an assessment tool.

The purpose of the current article was to sharpen and elaborate discussion of PLOC by modeling a "gradient of autonomy" from external to internal locus of causality on the basis of selfreported reasons for acting. Reasons for acting that reflected external, introjected, identified, or intrinsic impetus for action were examined for an ordered pattern reflecting an underlying continuum. The viability of a model of locus of causality was demonstrated in two domains: achievement and prosocial. Additionally, individual reason categories were shown to relate systematically to dimensions of interest with regard to these two domains. Specifically, in the achievement domain the reason 
categories showed predicted relations with a measure of intrinsic versus extrinsic motivation (Harter, 1981), a measure of perceived control (Connell, 1985), a measure of origin versus pawn dimensions (deCharms, 1976), and self- and other-rated motivation. The prosocial reason categories were related to empathy (Bryant, 1982), moral judgment (Rest, 1979), and to a measure of positive relatedness to significant others (Wellborn \& Connell, 1987).

An important aspect of the proposed model of PLOC is the credence it lends to theories of internalization. Various theories of internalization pose intermediate levels of "taking on" a value or behavioral regulation that represent neither heteronomy vis-à-vis the social environment nor autonomy and integration (e.g., Kelman, 1958; Schafer, 1968). Within the current data, these intermediate levels were shown to fall appropriately in line along a gradient of autonomy. Such data suggest that performing an act from approval concerns or avoidance of "feeling bad about oneself" is a relatively common form of self-control and value enforcement that is qualitatively different from either direct external regulation or more autonomous forms of self-regulation, such as identification or intrinsic motivation.

The usefulness of the proposed model of PLOC has been evidenced in several studies beyond the data presented here. Grolnick and Ryan (1987), for example, showed that a weighted sum of reason categories in the achievement domain (a relative autonomy index) was highly correlated with elementary school children's long-term memory for grade-level text material, particularly when that material was presented in the absence of any external pressures or constraints. In another study, Connell and Ilardi (1987) demonstrated that introjection was the type of reason that most strongly predicted whether children would inflate their perceived competence beliefs in the academic domain. More recently, Grolnick and Ryan (1989) have shown that parent styles characterized by support of autonomy and positive involvement are associated with more autonomously oriented reasons for behaving within the academic domain. Such studies attest to the importance of a differentiated model of PLOC in the study of motivational dynamics and their effects on selfrelated and behavioral variables.

The present studies of PLOC were based solely on structured self-reports of reasons for action. We used reasons because of their phenomenal accessibility and because of their conceptual importance in the realm of intrapersonal perception (Buss, 1978). However, it is also clear, particularly with respect to the phenomenon of introjection, that many of the processes reflecting intermediate levels of internalization (involving guilt, rigid standards, anxiety avoidance, etc.) are subject to distortion or biased reporting. They are indeed often more accessible through clinical methods or study of language locution (Schafer, 1976) than through self-report. Accordingly, the method used in this study needs to be seen for its heuristic but perhaps clinically limited value. Future research might fruitfully apply other methods of investigation that more fully access the motives that underlie action in internalization-relevant domains.

It should also be noted that a reason model of PLOC would not be expected to generalize to all domains of behavior, or perhaps to all developmental levels. We specifically suggest that such models will be most appropriately applied within those behavior- or value-acquisition domains where internalization processes occur. The current studies are, however, insufficient to confirm that hypothesis. Rather, their value lies in the demonstration that in at least two domains, achievement and prosocial behaviors, a differentiated PLOC model can meaningfully apply, and it has a structure consisting of graded points that fall along an underlying dimension of autonomy.

\section{References}

Bem, D. J. (1972). Self-perception theory. In L. Berkowitz (Ed.), Advances in experimental social psychology (Vol. 6, pp. 1-62). New York: Academic Press.

Benson, P. (1987). Freedom and value. Journal of Philosophy, 9, 465488.

Bridgman, P. W. (1959). The way things are. Cambridge, MA: Harvard University Press.

Bryant, B. K. (1982). An index of empathy for children and adolescents. Child Development, 53, 413-425.

Buhrmester, D. (1980). The Children's Concern Inventory. Unpublished manuscript, University of Denver.

Buss, A. R. (1978). A conceptual critique of attribution theory. Journal of Personality and Social Psychology, 36, 1311-1321.

Chandler, C. L., \& Connell, J. P. (1987). Children's intrinsic, extrinsic and internalized motivation: A developmental study of behavioral regulation. British Journal of Developmental Psychology, 5, 357-365.

Collins, B. E. (1977). Internalization: Towards a micro-social psychology of socialization or enduring behavior control. Unpublished manuscript, University of California, Los Angeles.

Connell, J. P. (1985). A new multidimensional measure of children's perceptions of control. Child Development, 56, 1018-1041.

Connell, J. P., \& Ilardi, B. (1987). Self-system concomitants of discrepancies between children's and teachers' evaluations of academic competence. Child Development, 58, 1297-1307.

Connell, J. P., \& Ryan, R. M. (1984). A developmental theory of motivation in the classroom. Teacher Education Quarterly, 11, 64-77.

Connell, J. P., \& Ryan, R. M. (1987). Development within the context of schools. International Society for the Study of Behavioral Development Newsletter (2, Serial No. 12).

Connell, J. P., \& Wellborn, J. G. (in press). Competence, autonomy, and relatedness: A motivational analysis of self-system processes. In $\mathbf{M}$. Gunnar \& A. Sroufe (Eds.), Self processes in development: $M$ innesota Symposium on Child Psychology (Vol. 23). Hillsdale, NJ: Erlbaum.

DeCharms, R. (1968). Personal causation: The internal affective determinants of behavior. New York: Academic Press.

DeCharms, R. (1976). Enhancing motivation: Change in the classroom. New York: Irvington.

DeCharms, R. (1981). Personal causation and locus of control: Two different traditions and two uncorrelated measures. In H. M. Lefcourt (Ed.), Research with the locus of control construct. Vol. I: Assessment methods (pp. 337-358). New York: Academic Press.

Deci, E. L., Nezlek, J., \& Sheinman, L. (1981). Characteristics of the rewarder and intrinsic motivation of the rewardee. Journal of Personality and Social Psychology, 40, 1-10.

Deci, E. L., \& Ryan, R. M. (1985). Intrinsic motivation and self-determination in human behavior. New York: Plenum Press.

Deci, E. L., \& Ryan, R. M. (1987). The support of autonomy and the control of behavior. Journal of Personality and Social Psychology, 53, 1024-1037.

Eisenberg, N. (1982). The development of reasoning regarding prosocial behavior. In N. Eisenberg (Ed.), The development of prosocial behavior. New York: Academic Press.

Eisenberg-Berg, N. (1979). Development of children's prosocial moral judgment. Developmental Psychology, 15, 128-137.

English, H., \& English, A. C. (1958). A comprehensive dictionary of psychological and psychoanalytic terms. New York: David McKay. 
Feshbach, N., \& Roe, K. (1968). Empathy in six- and seven-year olds. Child Development, 39, 133-145.

Grolnick, W. S., \& Ryan, R. M. (1987). Autonomy in children's learning: An experimental and individual difference investigation. Journal of Personality and Social Psychology, 52, 890-898.

Grolnick, W. S., \& Ryan, R. M. (1989). Parent styles associated with children's self-regulation and competence in school. Journal of Educational Psychology, 81, 143-154.

Guttman, L. (1954). A new approach to factor analysis: The radex. In P. Lazarfeld (Ed.), Mathematical thinking in the social sciences (pp. 258-348). New York: Free Press of Glencoe.

Harre, R. (1984). Personal being: A theory for individual psychology. Cambridge, MA: Harvard University Press.

Harter, S. (1981). A new self-report scale of intrinsic versus extrinsic orientation in the classroom: Motivational and informational components. Developmental Psychology, 17, 300-312.

Harter, S., \& Connell, J. P. (1984). A model of the relationships among children's academic achievement and their self-perceptions of competence, control, and motivational orientation. In J. Nicholls (Ed.), The development of achievement motivation (pp. 214-250). Greenwich, CT: JAI Press.

Heider, F. (1958). The psychology of interpersonal relations. New York: Wiley.

Kelman, H. C. (1958). Compliance, identification and internalization, three processes of attitude change. Journal of Conflict Resolution, 2, 51-60.

Kohlberg, L. (1969). Stage and sequence: The cognitive-developmental approach to socialization. In D. A. Goslin (Ed.), Handbook of socialization theory and research (pp. 347-480). Chicago: Rand McNally.

Krathwohl, D. R., Bloom, B. S., \& Masia, B. B. (1974). Taxonomy of educational objectives, handbook II: Affective domain. New York: David McKay.

Lepper, M. R. (1983). Social-control processes and the internalization of social values: An attributional perspective. In E. T. Higgins, D. N. Ruble, \& W. W. Hartup (Eds.), Social cognition and social development (pp. 294-330). New York: Cambridge University Press.

Lewis, H. B. (1971). Shame and guilt in neurosis. New York: International Universities Press.

McNemar, Q. (1962). Psychological statistics. New York: Wiley.

Mehrabian, A., \& Epstein, N. (1972). A measure of emotional empathy. Journal of Personality, 40, 525-543.

Meissner, W. W. (1981). Internalization in psyxhoanalysis. New York: International Universities Press.

Parsons, T. (1952). The superego and the theory of social systems. Psychiatry, 15, 15-25.

Peters, R. S. (1958). The concept of motivation. London: Routledge \& Kegan Paul.

Pfander, A. (1967). Phenomenology of willing and motivation. Evanston, IL: Northwestern University Press.

Radke-Yarrow, M., Zahn-Waxler, C., \& Chapman, M. (1983). Children's prosocial disposition and behavior. In E. M. Hetherington (Ed.), Handbook of child psychology: Vol. 4. Socialization, personality and social development (4th ed., pp. 469-546). New York: Wiley.
Rest, J. R. (1979). Revised manual for the Defining Issues Test. Minneapolis: Minnesota Moral Research Projects.

Reykowski, J. (1982). Social motivation. Annual Review of Psychology, 33, 123-154.

Reykowski, J., \& Smolenska, Z. (1980). Personality mechanisms of prosocial behavior. Polish Psychological Bulletin, 11, 219-230.

Rogers, C. (1965). Client centered therapy. Boston: Houghton Mifflin.

Ryan, R. M. (1982). Control and information in the intrapersonal sphere: An extension of cognitive evaluation theory. Journal of Personality and Social Psychology, 43, 450-461.

Ryan, R. M., Chandler, C., Connell, J. P., \& Deci, E. L. (1983, April). Internalization and motivation: Some preliminary research and theoretical speculations. Paper presented at the annual meeting of the Society for Research in Child Development, Detroit, MI

Ryan, R. M., Connell, J. P., \& Deci, E. L. (1985). A motivational analysis of self-determination and self-regulation in education. In C. Ames \& R. E. Ames (Eds.), Research on motivation in education: The classroom milieu (pp. 13-51). New York: Academic Press.

Ryan, R. M., Connell, J. P., \& Grolnick, W. S. (in press). When achievement is not intrinsically motivated: A theory of self-regulation in school. In A. K. Boggiano \& T. S. Pittman (Eds.), Achievement and motivation: A social-developmental perspective. New York: Cambridge University Press.

Ryan, R. M., \& Grolnick, W. S. (1986). Origins and pawns in the classroom: Self-report and projective assessments of individual differences in children's perceptions. Journal of Personality and Social Psychology, 50, 550-558.

Ryan, R. M., \& Lynch, J. (1989). Emotional autonomy versus detachment: Revisiting the vicissitudes of adolescence and young adulthood. Child Development, 60, 340-356.

Schafer, R. (1968). Aspects of internalization. New York: International Universities Press.

Schafer, R. (1976). A new language for psychoanalysis. New Haven, CT: Yale University Press.

Skinner, E. A., \& Chapman, M. (1987). Resolution of a developmental paradox: How can perceived internality increase, decrease, and remain the same across middle childhood? Developmental Psychology, $23,44-48$.

Strawson, P. F. (1959). Individuals. London: Methuen.

Tero, P., \& Connell, J. P. (1984, April). Children's academic coping inventory: A new self-report measure. Paper presented at American Educational Research Association, Montreal.

Turiel, E. (1977). Distinct conceptual and developmental domains: Social convention and morality. In C. B. Keasey (Ed.), Nebraska Symposium on Motivation (pp. 77-116). Lincoln: University of Nebraska Press.

Wellborn, J. G., \& Connell, J. P. (1987). A manual for the Rochester Assessment Package for Schools. Unpublished manuscript, University of Rochester. 